УДК 550.47:574:504.064.36(470+571)

\title{
СОДЕРЖАНИЕ РТУТИ В ЭПИФИТНЫХ ЛИШАЙНИКАХ НА ТЕРРИТОРИИ РЕСПУБЛИКИ КРЫМ
}

\author{
Евстафьева Елена Владимировна', \\ e.evstafeva@mail.ru
}

\author{
Богданова Анна Михайловна', \\ annuta2607@yandex.ru
}

\section{Большунова Татьяна Сергеевна, BolshunovaTS@gmail.com}

\section{Барановская Наталья Владимировна nata@tpu.ru}

\author{
Осипова Нина Александровна \\ osipova@tpu.ru \\ верситет им. В.И. Вернадского),

1 Медицинская академия им. С.И. Георгиевского (структурное подразделение ФГАОУ ВО Крымский Федеральный Уни-

В продолжение биомониторинговых исследований ртути на территории Крымского полуострова, направленных на реализацию системного подхода к изучению ее распределения между компонентами биосферы и разработки региональных экологических нормативов этого и других металлов, проведено определение содержания ртути в эпифитных лишайниках, являющихся природными планшетами атмосферной эмиссии тяжелых металлов.

Цель: определить и оценить содержание ртути в пробах эпифитных лишайников, отобранных в центральном, южном, юго-восточном и восточном регионах Крымского полуострова.

Методы. Содержание ртути в лишайниках видов Xanthoria parietina, Evernia prunastri и Evernia mesomorpha определяли атомноабсорбционным методом с использованием анализатора ртути с зеемановской коррекцией неселективного поглощения «РА915М», пиролитической приставки «ПИРО-915+» и пакета программ RA915Р в МИНОЦ «Урановая геология» Томского политехнического университета, и методом масс-спектрометрии с индуктивно связанной плазмой в аккредитованном химико-аналитическом центре «Плазма» (г. Томск).

Результаты. Содержание ртути в эпифитных лишайниках, отобранных преимущественно на заповедных территориях южного региона Крыма, а также в парковых зонах городов его центрального, юго-восточного и восточного регионов и вблизи очистных сооружений варьировало в пределах от 0,054 до 0,306 мкг/ги не отличалось от фоновых значений содержания ртути в лишайниках на других территориях Российской Федерации. В то же время наблюдалась существенная неоднородность в территориальном распределении ртути: в лишайниках парковых зон на территории городов ее содержание колебалось в пределах 0,063-0,088 мкг/Г, а в горных и предгорных районах южного Крыма было выше в 2 раза. Это может быть связано с геоморфологическими и геохимическими особенностями Главной гряды (глубинные разломы ортогональной системы с ртутными рудопроявлениями и зонами геодинамической активности), а также ее барьерной функцией для воздушных масс, насыщенных морскими аэрозолями, содержащими ртуть. Помимо этого, как свидетельствуют данные моделирования экспертной группы Конвенции LRTAP, существенный вклад может вносить трансграничный перенос ртути. Вариабельность содержания ртути в лишайниках на условно фоновых территориях и интенсивное технологическое развитие Крыма диктуют необходимость дифференцированного подхода к оценке экологической ситуации в отношении этого глобального и опасного загрязнителя на различного типа территориях Крымского полуострова.

\section{Ключевые слова:}

Ртуть, лишайник, биосубстрат, биоиндикатор, Республика Крым.

\section{Введение}

Глобальная трансформация биосферы и обострение в связи с этим экологических проблем делает остро актуальным использование наиболее чувствительных индикаторов антропогенного воздействия на окружающую среду и здоровье человека. С точки зрения оценки негативного влияния на организм человека значительный интерес предста- вляют биомониторинговые исследования содержания загрязнителей в тканях организма человека, как конечного консумента большинства биогеохимических трофических цепей, по которым осуществляется круговорот поллютантов. В то же время существует необходимость ориентации и на другие чувствительные индикаторы экологического состояния территорий, что позволит дополнить, 
сопоставить и уточнить имеющуюся в регионе экологическую ситуацию, а также учесть полученную информацию при разработке и определении региональных экологических нормативов содержания загрязнителя с учетом природной и антропогенной специфики региона.

K числу наиболее опасных глобальных загрязнителей биосферы относится ртуть, в отношении которой рекомендуется первоочередная инвентаризация выбросов и оценка загрязнения этим металлом территорий [1-5]. И, несмотря на отсутствие существенных промышленных источников загрязнения ртутью на территории Крымского полуострова, остается вероятность значимого загрязнения в результате сжигания угля и образования твердых отходов [6], а также трансграничного переноса [7].

Ранее нами проведено биомониторинговое исследование, которое показало, что при отсутствии значимых отклонений от условной допустимой нормы имеется неоднородное распределение содержания ртути в волосах жителей разных территорий Крымского полуострова [8]. Учитывая также то обстоятельство, что влияние ртути на функционирование систем организма выявляется и при очень низком содержании [9-11], а сочетанное воздействие ряда химических факторов в низких дозах может оказывать синергический эффект, дальнейшее изучение ситуации на Крымском полуострове в отношении этого тяжелого металла остается актуальным. 0 том, что такой риск небезоснователен, свидетельствуют негативные тенденции в изменении состояния здоровья населения в Республике Крым [12], как и во многих регионах мира и Российской Федерации. Особенно актуально это в климатических условиях Крымского полуострова, где высокая температура может увеличивать и без того отличающуюся высокой мобильностью и склонностью к комплексообразованию ртуть [13].

В связи с этим с целью дальнейшего изучения распространенности содержания ртути в компонентах биосферы нами предпринято исследование по определению этого металла в одном из наиболее чувствительных индикаторов атмосферной эмиссии - эпифитных лишайниках [14-17], которые служат своего рода природным планшетом, поглощающим ртуть из атмосферных выпадений [18-20].

\section{Материалы и методики исследования}

Исходя из ранее полученных результатов неоднородного распределения содержания ртути в волосах жителей разных регионов Крыма, а также учитывая то обстоятельство, что именно морская и океаническая вода являются средой глобального ртутного загрязнения [21-23], пробы эпифитных лишайников были отобраны на разного типа территориях южного, юго-восточного, восточного и центрального регионов Крымского полуострова, преимущественно прибрежных. Большая часть проб была отобрана на участках природных экоси- стем, которые можно отнести к фоновым (контрольным), поскольку они расположены на заповедных территориях: горные массивы Ай-Петри, Чатыр-Даг, Демерджи (рис. 1). Остальные пробы были отобраны на урбанизированных территориях (города Симферополь, Керчь, Феодосия), главным образом в парковых зонах, удаленных на расстояние не менее 1 км от возможных источников ртутного загрязнения за исключением двух площадок в г. Феодосия, расположенных вблизи с водопроводно-очистными сооружениями, которые рассматривались как возможный источник ртутного загрязнения.

Образцы эпифитных лишайников вида Evernia mesomorpha отобраны летом 2015 г. на горных массивах южного берега Крыма: территории верхнего (1500 м над у.м.) и нижнего плато Чатыр-Дага (1300 м над у.м.) Крымского природного заповедника, а также на Южном склоне Демерджи (1239 м над у.м.). Образцы отбирали с редкостойных молодых деревьев Сосны крымской (Pinus Pallasiana) горы Чатыр-Даг, с боярышника Поярковой (Crataegus pojarkovae K.) с горных склонов Демерджи. Всего в 2015 г. отобрано 10 проб.

Отбор проб эпифитных лишайников видов Xanthoria parietina, Evernia prunastri и Evernia mesomorpha в 2016-2017 гг. осуществлялся как на территории природных экосистем - с. Перевальное (Красные пещеры), Крымского природного заповедника, г. Ай-Петри, так и урбоэкосистем парковые зоны г. Симферополь, г. Керчь, г. Феодосия - по нерегулярной сетке на высоте человеческого роста от поверхности почвы с целью снижения вероятности загрязнения образцов почвами. Виды эпифитных лишайников определены в г. Симферополь по [24]. В 2016-2017 гг. отобрано 11 проб.

Отбор и подготовка к анализу 21 пробы лишайников осуществлены согласно рекомендациям [25-28] и включали высушивание при комнатной температуре, измельчение и перемешивание для достижения наибольшей однородности материала, что обеспечивало представительность выборки.

Содержание ртути в лишайниках, отобранных в 2015 г., определяли методом масс-спектрометрии с индуктивно связанной плазмой в аккредитованном химико-аналитическом центре «Плазма» (г. Томск). Определение содержания ртути проводили в 10 образцах сухого вещества лишайников. Ошибка определения ртути не превысила $10 \%$. Всего проанализировано 30 образцов лишайников (3 повторности измерений).

Содержание ртути в лишайниках, отобранных в 2016-2017 гг., определяли атомно-абсорбционным методом с использованием анализатора ртути с зеемановской коррекцией неселективного поглощения «PA-915M», пиролитической приставки «ПИРО-915+» и пакета программ RA915P в Международном инновационном научно-образовательном центре «Урановая геология» Томского политехнического университета. Ошибка определения 


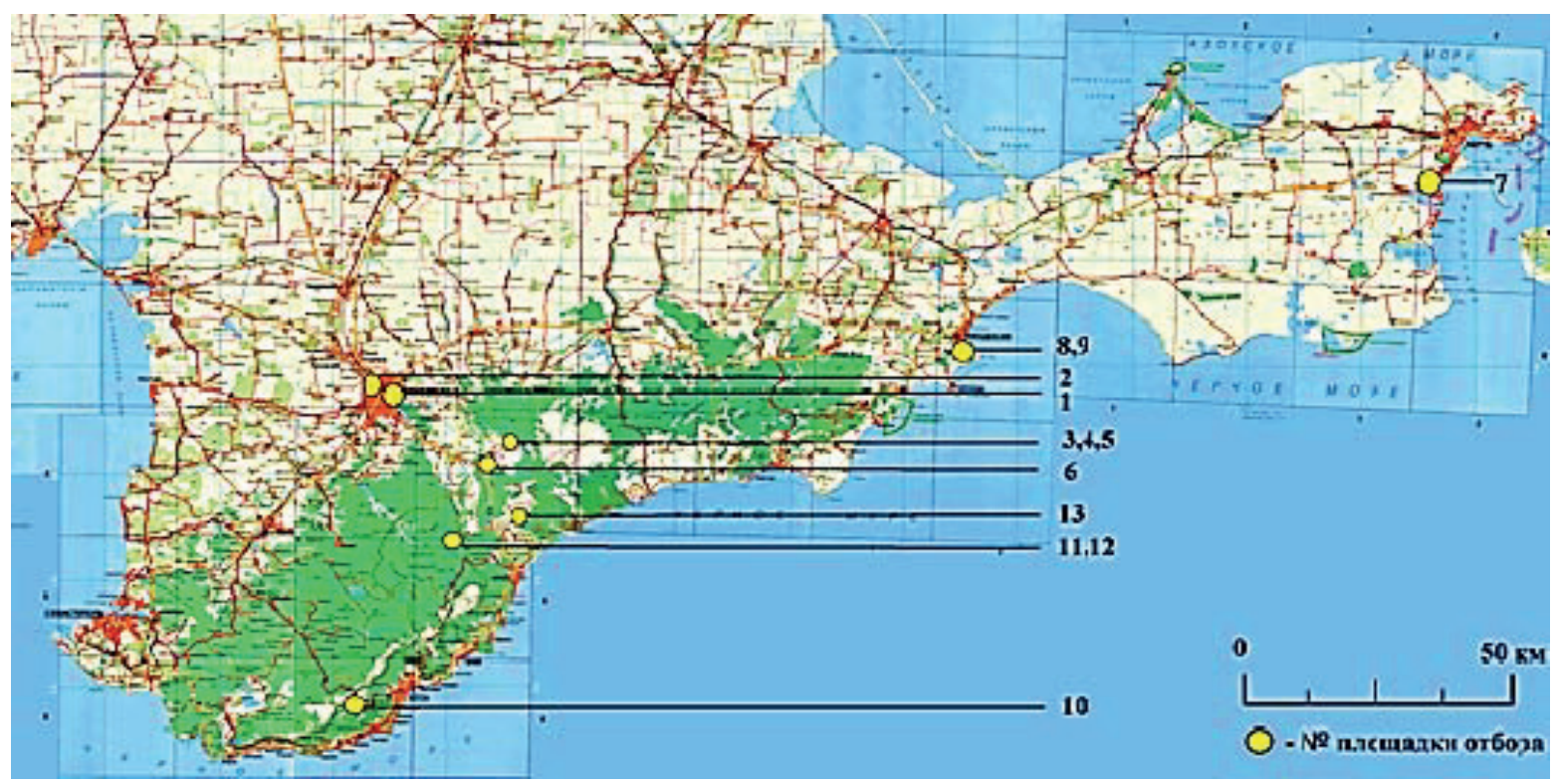

Puс. 1. Расположение площадок отбора проб лишайников на территории Республики Крым

Fig. 1. Location of plots of lichens samples selection in the territory of Crimea Republic

таблица. Содержание ртути в лишайниках, отобранных на территории Крымского полуострова

Table. $\quad$ Mercury content in lichens in the territory of Crimean peninsular

\begin{tabular}{|c|c|c|c|c|c|}
\hline $\begin{array}{l}\text { Локализация площадки } \\
\text { отбора, год отбора } \\
\text { Location of selection plot, } \\
\text { year of selection }\end{array}$ & $\begin{array}{c}\text { № пло- } \\
\text { щадки } \\
\text { № } \\
\text { of plot }\end{array}$ & $\begin{array}{l}\text { Характеристика площадки отбора } \\
\text { Characteristic of selection plot }\end{array}$ & \begin{tabular}{|c|} 
Концентрация \\
ртути, мкг / \\
Mercury con- \\
centration, \\
$\mathrm{mkg} / \mathrm{g}$
\end{tabular} & $\begin{array}{l}\mathrm{M} \pm \mathrm{SD} \\
\mathrm{MKr} / \mathrm{\Gamma} \\
\mathrm{M} \pm \mathrm{SD} \\
\mathrm{mkg} / \mathrm{g}\end{array}$ & $\begin{array}{l}\text { Количе- } \\
\text { ство проб } \\
\text { Amount of } \\
\text { samples }\end{array}$ \\
\hline $\begin{array}{l}\text { г. Симферополь } \\
\text { Simferopol } \\
2016-2017\end{array}$ & $\begin{array}{l}1 \\
2\end{array}$ & \begin{tabular}{|c|} 
Ботанический сад, парковая зона, (260 м над у.м.) \\
Вotanic garden, park zone (260 m above sea level) \\
Парковая зона у р. Салгир, 20 м от дороги, (240 м над у.м.) \\
Park zone near Salgir river, 20 m from the road, (260 m above sea level)
\end{tabular} & $\begin{array}{l}0,088 \\
0,063\end{array}$ & $0,075 \pm 0,018$ & $\begin{array}{l}1 \\
1\end{array}$ \\
\hline $\begin{array}{c}\text { Красные пещеры, } 3 \text { км } \\
\text { от с. Перевальное- } 2, \\
\text { Симферопольский район } \\
\text { Red caves, } 3 \mathrm{~km} \text { from Pere- } \\
\text { valnoe-2, Simferopol di- } \\
\text { strict } 2016-2017\end{array}$ & $\begin{array}{l}3 \\
4 \\
5 \\
6\end{array}$ & $\begin{array}{c}\text { Водопад Су-Учхан, (570 м над у.м.) } \\
\text { Su-Uchkhan waterfall, (570 m аbove sea level) } \\
\text { Лесная зона, (516 м над у.м.) } \\
\text { Forest zone, (516 m above sea level) } \\
\text { Лесная зона, (475 м над у.м.) } \\
\text { Forest zone, (475 m above sea level) } \\
30 \text { м от дороги, (430 м над у.м.) } \\
30 \text { m from the road, (430 m above sea level) }\end{array}$ & $\begin{array}{l}0,101 \\
0,092 \\
0,127 \\
0,078\end{array}$ & $0,099 \pm 0,021$ & $\begin{array}{l}1 \\
1 \\
1 \\
1\end{array}$ \\
\hline $\begin{array}{c}\text { г. Керчь } \\
\text { Kerch } \\
2016-2017 \\
\end{array}$ & 7 & $\begin{array}{l}\text { Городской пляж, } 30 \text { м от моря, (1 м над у.м.) } \\
\text { City beach, } 30 \mathrm{~m} \text { from the sea, }(1 \mathrm{~m} \text { above sea level })\end{array}$ & 0,076 & 0,076 & 1 \\
\hline $\begin{array}{l}\text { г. Феодосия } \\
\text { Feodosia 2016-2017 }\end{array}$ & 8 & $\begin{array}{c}200 \text { м от бассейнов очистных сооружений, } \\
400 \text { м от моря, ( } 85 \text { м над у.м.) } \\
200 \mathrm{~m} \text { from the pools of treatment facilities, } \\
400 \mathrm{~m} \text { from the sea, ( } 85 \mathrm{~m} \text { above sea level) } \\
100 \text { м от бассейнов очистных сооружений, } \\
300 \text { м от моря, ( } 60 \text { м над у.м.) } \\
100 \mathrm{~m} \text { from the pools of treatment facilities, } \\
300 \mathrm{~m} \text { from the sea, ( } 60 \text { m above sea level) }\end{array}$ & $\begin{array}{l}0,054 \\
0,147\end{array}$ & $0,101 \pm 0,066$ & 2 \\
\hline $\begin{array}{c}\text { Гора Ай-Петри } \\
\text { Ai-Petri Mountain } \\
2016 \\
\end{array}$ & 10 & $\begin{array}{l}\text { Плато г. Ай-Петри (1200 м над у.м.), лесная зона } \\
\text { Plateau of Ai-Petri (1200 m above sea level), forest zone }\end{array}$ & 0,306 & 0,306 & 1 \\
\hline $\begin{array}{l}\text { Крымский природный } \\
\text { заповедник } \\
\text { Crimean nature } \\
\text { conservancy area } 2015\end{array}$ & 12 & $\begin{array}{c}\text { Верхнее плато г. Чатыр-Даг (1500 м над у.м.) } \\
\text { Upper plateau of Chatyr-Dag (1500 m above sea level) } \\
\text { Нижнее плато г. Чатыр-Даг (1300 м над у.м.) } \\
\text { Lower plateau of Chatyr-Dag (1300 m above sea level) }\end{array}$ & $\begin{array}{l}0,104 \\
0,161\end{array}$ & $0,131 \pm 0,040$ & $\begin{array}{l}2 \\
4\end{array}$ \\
\hline $\begin{array}{c}\text { Демерджи-яйла } \\
\text { Demerdzhi-Yaila } \\
2015 \\
\end{array}$ & 13 & $\begin{array}{l}\text { Южная Демерджи (1239 м над у.м.) } \\
\text { South Demerdzhi (1239 m above sea level) }\end{array}$ & 0,110 & $0,110 \pm 0,050$ & 4 \\
\hline
\end{tabular}


ртути не превысила $10 \%$. Всего проанализировано 33 образца лишайников (3 повторности измерений).

Навеску предварительно-измельченных и доведенных до воздушно-сухого состояния пробы лишайников видов Xanthoria parietina, Evernia prunastri и Evernia mesomorpha (2016-2017 гг.) с помощью кварцевой лодочки-дозатора вводили в приёмное гнездо термоблока ртутного атомизатора. В термоблоке происходит термическое разложение образца с одновременной атомизацией ртути. Приставка с помощью специального устройства соединена с анализатором ртути РА-915, где происходит определение ртути, при этом нижний предел обнаружения составляет 0,0025 мкг/г. Обработка результатов измерений осуществляется с помощью программного обеспечения "Рапид». Предварительными экспериментами в режиме «Форсаж» показано, что выбранный режим (скорость прокачки воздуха 0,8-1,2 л/мин., температура испарителя 680-740 ${ }^{\circ} \mathrm{C}$ ) обеспечивает полноту выделения ртути. В качестве аналога при проведении анализа используются ПНДФ16.1.2.23-2000 [29]. Для построения и контроля стабильности градуировочных характеристик при определении массовой доли ртути в твердых образцах лишайников использовали стандартный образец состава листа березы ЛБ-1, ГСО 8923-2007, С атг. $_{10} 0,037 \pm 0,006$ мкг $/ г$, $\mathrm{C}_{\text {изм }}=0,033 \pm 0,001 \mathrm{мкг} /$ г

Анализ полученных результатов проводили с использованием «Microsoft Office Excel 2007». Для описания полученных на всех площадках мониторинга данных использовали средние значения (M) и среднеквадратическое отклонение (SD), а также минимальные $(\min )$ и максимальные $(\max )$ значения концентраций ртути.

\section{Результаты исследования и обсуждение}

Содержание ртути в лишайниках, отобранных на различных участках центрального, южного, юго-восточного и восточного регионов Крымского полуострова варьировало в пределах от 0,054 до 0,306 мкг/г (таблица). При этом в лишайниках парковых зон на территории городов оно колебалось в пределах 0,063-0,088 мкг/г.

Такие величины сопоставимы с содержанием ртути в эпифитных лишайниках различных регионов Сибири, где, однако, наблюдали значительные различия в зависимости от района исследования: от 0,89 мкг/г в Читинской области до содержания ртути ниже предела обнаружения 0,001 мкг/г в лишайниках Алтайского края и районах ЯмалоНенецкого Автономного округа [30]. Однако при этом не указаны виды исследованных лишайников, в то время как показано, что их способность к аккумуляции ртути существенно различается. Сoдержание ртути в лишайниках тех же видов, что и рассматриваемые в настоящей статье, соответствует полученным нами данным для горных и предгорных территорий [31]. Низкие значения уровня ртути в эпифитных лишайниках $(0,01-0,31$ мкг/г) сопоставимы также с ее содержанием в эпигейных лишайниках водосборного бассейна Белого моря на территории Мурманской и Архангельской областей и Республики Карелия [32].

В целом анализ данных русскоязычной литературы [17, 33-37] показывает отсутствие значимых различий в выявляемых концентрациях ртути в эпифитных лишайниках разных регионов Российской Федерации и СНГ за исключением таких территорий, как, например, Урское хвостохранилище в Кемеровской области, где более высокие концентрации обусловлены нахождением объектов в пределах рудных полей с золотополиметаллической специализацией (рис. 2). В совокупности с данными, полученными в других регионах мира [16, 36], это дает основание для заключения о том, что наблюдаемые в лишайниках Крыма содержания ртути имеют преимущественно естественное происхождение, поскольку вблизи источников техногенного ртутного загрязнения оно значительно выше и составляет, как правило, более 1 мкг/г [38].

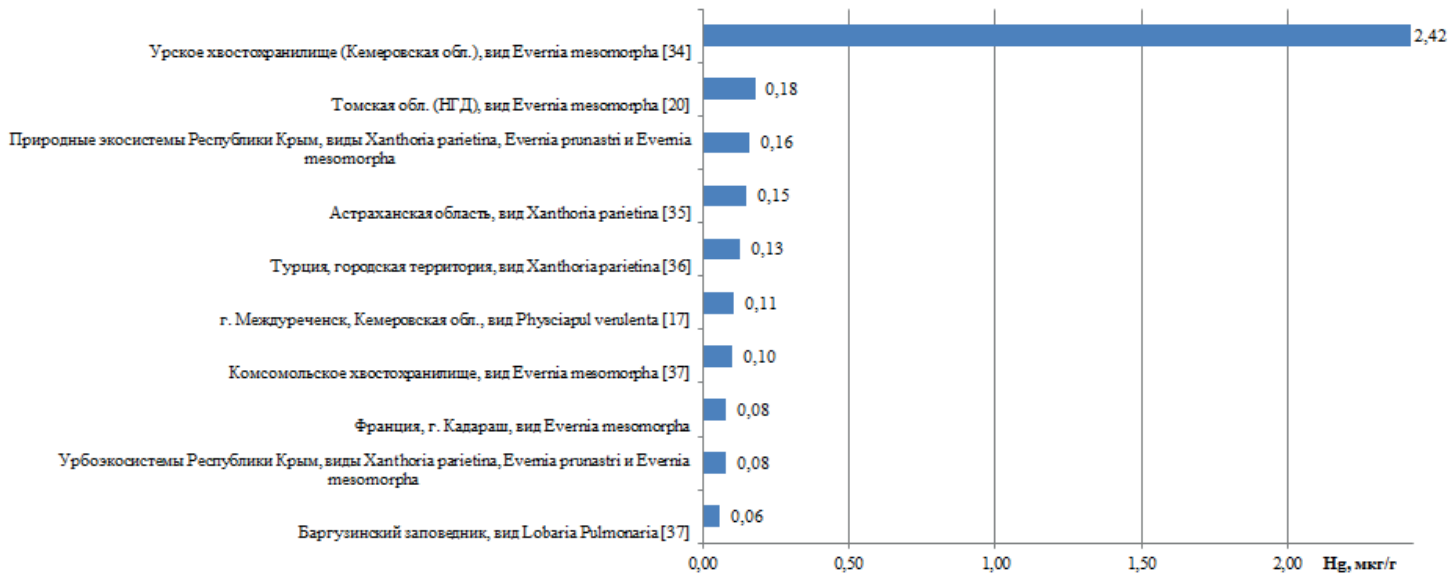

Pис. 2. Содержание ртути в лишайниках различных территорий Российской Федерации и Евразии, мкг/ح

Fig. 2. Mercury content in lichens from various territories of the Russian Federation and Eurasia, $\mathrm{mkg} / \mathrm{g}$ 


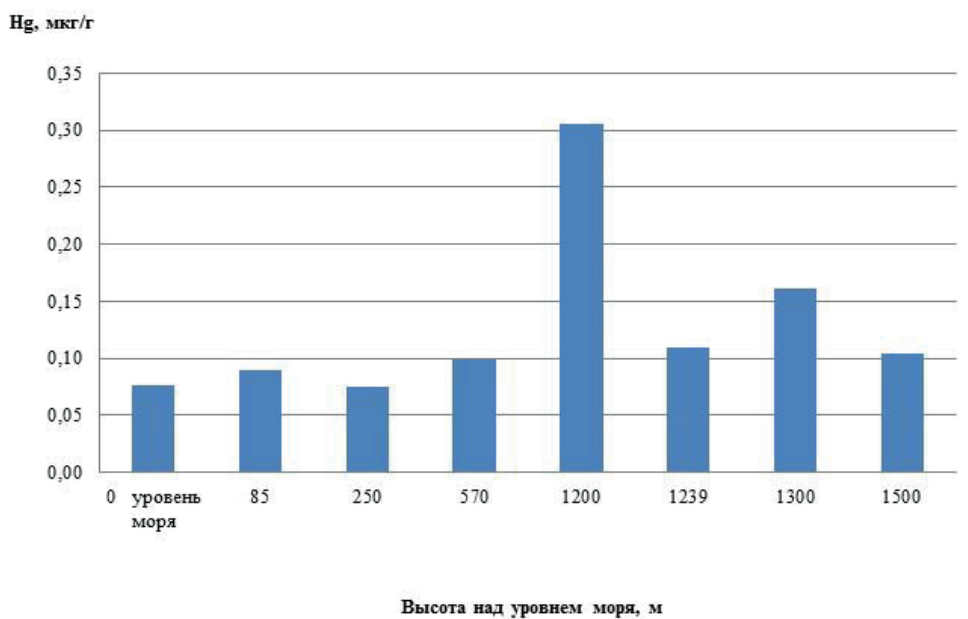

Рис. 3. Содержание ртути (мкг/г) в эпифитных лишайниках, произрастающих на разной высоте над уровнем моря

Fig. 3. Mercury content $(\mathrm{mkg} / \mathrm{g})$ in the epiphytic lichens located at different altitude above sea level

В то же время обращают на себя внимание довольно существенные территориальные различия в содержании этого металла в лишайниках, растущих на используемых в настоящем исследовании мониторинговых площадках Крымского полуострова. Так, наиболее высокие уровни содержания ртути выявлены на горных и предгорных территориях южного берега (рис. 3), причем эти величины сравнимы с содержанием в лишайниках, растущих вблизи источника антропогенного загрязнения (водопроводно-очистные сооружения в г. Феодосия). При этом в лишайниках, расположенных на высоте от 600 до 1500 м над уровнем моря, значения ртути превышали таковые в более низко растущих лишайниках (0-570 м) вдвое. Стоит отметить, что максимальные величины были характерны для лишайников, произрастающих не на самой большой из исследованных высот (г. Ай-Петри), однако с наиболее близким расположением к морскому побережью.

Более высокие концентрации ртути в пробах, отобранных на территориях Южного побережья, в сравнении с площадками, расположенными в центральной части Крымского полуострова (г. Симферополь), равно как и данные ранее проведенных биомониторинговых исследований содержания ртути в волосах жителей разных регионов, предположительно связаны с тем, что в приморских районах наряду с традиционными источниками (транспорт, промышленность) в химическое загрязнение атмосферного воздуха значительный вклад вносят токсические вещества, попадающие в атмосферу с морскими аэрозолями $[1,2]$. Считается, что для регионов с преимущественной розой ветров «море-берег», к которым относятся в течение значительной части года морские побережья, эта проблема приобретает особую актуальность [28], особенно в отношении ртути, которая более подвержена эмиссии и легко переносится на большие расстояния от локального источника загрязнения [7].
Нельзя также исключить влияния на прибрежных территориях антропогенных источников (карьеры по разработке стройматериалов, промышленные предприятия, аграрно-промышленные и коммунально-бытовые объекты) [39].

В пользу того, что именно морские аэрозоли могут быть преимущественным «поставщиком» ртути, свидетельствуют и данные о распределении общей массы ртути между компонентами биосферы в Крыму. Так, согласно А.И. Радченко [33], общая масса ртути в биосфере Крыма оценивается в $10 \cdot 10^{-9} \mathrm{~T}$, из них $0,2 \cdot 10^{-9} \mathrm{~T}$ находится в коренных породах, $0,34 \cdot 10^{-9} \mathrm{~T}-$ в почвах, а наибольшая доля $-1,12 \cdot 10^{-9}$ и $8,5 \cdot 10^{-9} \mathrm{~T}-$ приходятся на гидросферу и атмосферу соответственно.

В то же время содержание ртути в лишайниках на территории г. Керчи, расположенного на восточном побережье Черного моря, было низким и не отличалось от данных, характерных для других урбанизированных территорий. Это может быть обусловлено разнообразием типов территорий, которое присуще Крымскому полуострову. Так, согласно разработанной классификации геохимических ландшафтов Республики Крым [39], ртуть может являться даже дефицитным элементом для таких ландшафтных зон, как прибрежные лиманно-морская зона низменной солонцово-солончаковой равнины, сухие степи слаборасчленённой равнины, в том числе присивашские, лесостепные, аквальные озерно-(лиманно-) морские. В то же время авторами выделены низкогорные широколиственно-лесные зоны, для которых характерно избыточное содержание ртути, и среднегорные горнолесные ландшафты, где ртуть может считаться элементом накопления, с чем согласуются и наблюдаемые нами результаты анализа содержания ртути в лишайниках. Последнее объясняется также тем обстоятельством, что для горного и предгорного Крыма характерно наличие природных геохимических источников ртути: глубинные разломы 
ортогональной системы с ртутными рудопроявлениями и зонами геодинамической активности.

По всей видимости, представленные в данной работе результаты свидетельствуют о необходимости дифференцированного подхода к анализу ситуации с учетом неоднородности природных условий такой территории, как Крымский полуостров.

Помимо рассмотренных местных источников ртути на данных территориях существенный вклад может вносить ее трансграничный перенос. Главная гряда Крымских гор выполняет роль естественного барьера для переносимых воздушных масс, содержащих ртуть. Так, на сопредельных с Крымским полуостровом территориях Черноморского побережья (Южный федеральный округ, приграничные районы Ростовской области, Краснодарского края) происходят трансграничные выпадения ртути, составляющие до 25 и более г/км ${ }^{2} /$ год [40], а по данным моделирования экспертов Конвенции о трансграничных переносах атмосферных загрязнителей на дальние расстояния трансграничные выпадения ртути на южном берегу Крыма в 2010 г. составляли 15-20 г/км ${ }^{2} /$ год, и останутся приблизительно на том же уровне к 2020 г., что вдвое выше выпадений в равнинном Крыму [7].

Таким образом, как невысокие величины обнаруженного содержания ртути, так и анализ возможных ее источников дает основание для заключения о преимущественно естественном происхождении ртути в лишайниках на исследованных территориях. Тем не менее, разный вклад естественных источников ртути в ртутное загрязнение лишайников на различных территориях, трансграничный перенос и антропогенные источники, роль которых в связи с развитием Республики Крым будет только возрастать в ближайшее время, свидетельствуют о необходимости дальнейшего изучения распределения этого токсичного элемента в компонентах экосистем Крымского полуострова.

\section{Заключение}

Содержание ртути в лишайниках, отобранных преимущественно на заповедных территориях южного региона Крыма, а также в парковых зонах городов центрального, восточного и вблизи очистных сооружений юго-восточного регионов полуострова, варьировало в пределах от 0,054 до 0,306 мкг/г. Сопоставление с концентрациями

\section{СПИСОК ЛИТЕРАТУРЫ}

1. Spranger T., Lorenz U., Gregor H.D. Manual on methodologies and criteria for modeling and mapping critical loads and levels and air pollution effects, risks and trends. - Berlin: Fed. Environ. Agency (Umweltbundesamt), UBA-Texte, 2004. - 307 p.

2. Zhao J., Becker P.R., Meng X.Z. Securing a Strategy to Monitor Emerging Pollutants in the Regional and Global Environment: 2013 International Conference on Environmental Specimen Banks // Environmental Science and Pollution Research International. - 2015. - V. 22. - № 3. - P. 1555-1558.

3. IMOC - Inter organizational Programme for the Sound Management of Chemicals. A cooperative agreement among UNEP, ILO, ртути в лишайниках на территории Российской Федерации и других стран дает основание для заключения о преимущественно естественном происхождении наблюдаемых величин. В то же время имеет место существенная неоднородность в территориальном распределении ртути: в лишайниках парковых зон на территории городов ее содержание колебалось в пределах 0,063-0,088 мкг/г, а в горных и предгорных районах южного Крыма было выше в 2 раза. Это обусловлено высоким разнообразием типов территорий, присущим Крымскому полуострову, в частности, геоморфологическими и геохимическими особенностями Главной гряды (глубинные разломы ортогональной системы с ртутными рудопроявлениями и зонами геодинамической активности), а также ее барьерной функцией для воздушных масс, насыщенных морскими аэрозолями, содержащими ртуть. Помимо локальных источников ртути существенный вклад может вносить ее трансграничный перенос. По данным моделирования международной экспертной группы Конвенции о трансграничных переносах атмосферных загрязнителей ее выпадения на южнобережной территории Крыма может вдвое превышать величины на равнинных территориях и составлять до 20 г/км² $/$ год.

Такая неоднородность распределения ртути на условно фоновых территориях наряду с интенсивным технологическим развитием Крыма в последние годы диктует необходимость дифференцированного подхода и особенно внимательного отношения к мониторинговым исследованиям и контролю ситуации в отношении такого глобального и опасного загрязнителя, как ртуть.

Настоящая работа выполнена при поддержке Програмлы развития Федерального государственного автономного образовательного учреждения высшего образования "Крымский федеральный университет им. В.И. Вернадского» на 2015-2024 годы в рамках реализации академической мобильности по проекту «Развитие научных исследований в области экспериментальной медицины РНИЭМ» в ФГАОУ ВО Национальный исследовательский Томский политехнический университет в 2016 г.; в рамках програмлы повышения конкурентоспособности Наиионального исследовательского Томского политехнического университета среди ведущих мировых исследовательских иентров; определение содержания ртути в лишайниках выполнено при финансовой поддержке РФФИ в рамках научного проекта № 18-29-24212 \18.

FA0, WHO, UNID0, UNITAR and OECD. Global Mercury Assessment. - Geneva: UNEP Chemicals, 2002. - 258 p.

4. Минаматская конвенция о ртути // ЮНЕП, 00Н, 2013. - 65 с. URL: http://www.mercuryconvention.org/Portals/11/documents/Booklets/Minamata_convention_Russian.pdf (дата обращения: 19.06.2018).

5. Пилотный проект по формированию кадастра ртутных загрязнений в РФ. URL: https://www.mercury2017.ru/dokumenty (дата обращения: 19.06.2018).

6. Ртутное загрязнение в России: проблемы и рекомендации / под ред. А. Романова, 0. Сперанской, 0. Цитцер. - Коломна: Коломенская типография, 2016. - $118 \mathrm{c.}$ 
7. Slootweg J., Maximilian P., Hettelingh J. Progress in the modelling of critical thresholds and dynamic modelling, including im pacts on vegetation in Europe // CCE Status Report. - 2010. $182 \mathrm{p}$.

8. Экологические и биомониторинговые исследования ртути в Крымском регионе / Е.В. Евстафьева, Н.В. Барановская, С.Л. Тымченко, А.М. Богданова, Г.П. Нараев, Н.А. Сологуб, Д.В. Наркович // Известия Томского политехнического университета. Инжиниринг георесурсов. - 2017. - Т. 328. - № 3. C. $96-105$.

9. Евстафьева Е.В. Оценка экологического риска для здоровья на территории Республики Крым // Проблемы анализа риска. 2014. - T. 11. - № 5. - C. 30-38.

10. Евстафьева И.А. Особенности функционального состояния центральной нервной и сердечнососудистой систем в связи с содержанием тяжелых металлов в организме подростков: дис. ... канд. биол. наук. - Симферополь, 2003. - 130 с.

11. Слюсаренко А.Е. Иммунологическая реактивность организма в различных условиях техногенного загрязнения среды тяжелыми металлами: дис. ... канд. биол. наук. - Симферополь, 2003. $-157 \mathrm{c}$.

12. Доклад «0 состоянии и охране окружающей среды на территории Республики Крым в 2016 году». - Ижевск: 000 «Принт-2», 2017. -300 c.

13. Интоксикация человеческого организма металлической ртутью / В.Г. Моисеенко, В.И. Радомская, С.М. Радомский, Ю.Г. Пискунов, Т.А. Савинова, А.В. Леншин // Вестник Дальневосточного отделения Российской академии наук. - 2004. № 3. - C. 100-110.

14. Element analysis of biological materials. Current problems and techniques with special reference to trace elements. Appendix II. Technical reports series. - Vienna: IAEA, 1980. - № 197. P. 351-367.

15. Kist A.A., Zhuk L.I. Human hair composition and the problems of global ecology. - Tashkent, USSR: Institute of Nuclear Physics of the Uzbek Academy of Sciences, 1991. - 60 p.

16. Bargagli R. Moss and lichen biomonitoring of atmospheric mercury: a review // Science of the Total Environment. - 2016. V. 572. - P. 216-231.

17. Исупова А.А., Ялалтдинова А.Р. Количественное определение содержания ртути в лишайнике вида Physciapul verulenta на примере промышленного города Междуреченска // Экологические проблемы региона и пути их решения: Материалы национальной научно-практической конференции «Эко-В00М». Омск, 2016. - C. 143-147.

18. Bargagli R. Trace Elements in Terrestrial Plants: an Ecophysiological Approach to Biomonitoring and Biorecovery. - B.: Springer, 1998. $-324 \mathrm{p}$.

19. Lichen monitoring as a potential tool in environmental forensics: case study of the $\mathrm{Cu}$ smelter and former mining town of Karabash, Russia / 0.W. Purvis, B.J. Williamson, B. Spiro, V. Udachin, I.N. Mikhailova, A. Dolgopolova // Geological Society, London, Special Publications. - 2013. - V. 384. - P. 133-136.

20. Mezhibor A.M., Bolshunova T.S., Rikhvanov L.P. Geochemical features of sphagnum mosses and epiphytic lichens in oil and gas exploitation areas (the case of Western Siberia, Russia) // Environmental Earth Sciences. - 2016. - V. 75. - № 18. - P. 1260.

21. Integrating Mercury Science and Policy in the Marine Context: Challenges and Opportunities / K.F. Lambert, D.C. Evers, K.A. Warner, S.L. King, N.E. Selin // Environmental Research. - 2012. - № 119. - P. 132-142.

22. Surveying mercury levels in hair, blood and urine of under 7-year old children from a coastal city in China / G. Chen, X. Chen, C. Yan, X. Wu, G. Zeng // International journal of environmental research and public health. - 2014. - V. 11. - № 11. P. 12029-12041
23. Биомониторинг прибрежных вод Черного моря / И.И. Руднева, Н.Ф. Шевченко, И.Н. Залевская, Н.В. Жерко // Водные ресурсы. - 2005. - Т. 32. - № 2. - С. 238-246.

24. Окснер А.Н. Определитель лишайников СССР. Морфология, систематика и географическое распространение. Вып. 2. - Л.: Наука, 1974. - 284 с.

25. Язиков Е.Г., Барановская Н.В., Игнатова Т.Н. Эколого-геохимическая оценка территории района города по данным биогеохимической съемки. - Томск: Изд-во Томского политехнического университета, 2009. - 32 с.

26. Bargagli R., Nimis P.L. Guidelines for the use of epiphytic lichens as biomonitors of atmospheric deposition of trace elements // Monitoring with Lichen - Monitoring Lichens. - Dordrecht: Kluwer, 2002. - P. 295-299.

27. Зырина Н.Г., Малахова С.Г. Методические рекомендации по проведению полевых и лабораторных исследований почв и растений при контроле загрязнения окружающей среды металлами. - М.: Гидрометеоиздат, 1981. - 187 с.

28. Разработка научных основ и создание экспериментального образца технологии оперативного контроля качества воздуха в приморских городах и курортных зонах / В.Б. Лапшин, М.А. Чичаева, Д.М. Полевщиков, И.С. Матвеева, Т.В. Гребенникова, М.В. Колесников, Г.Н. Чиквиладзе, С.С. Плетенев, А.В. Сыроешкин // Труды Государственного океанографического института. - 2009. - № 212. - С. 308-322.

29. Методика выполнения измерений массовой доли ртути в пробах пищевых продуктов, продовольственного сырья, кормов, комбикормов и сырья для их производства атомно-абсорбционным методом с использованием анализатора ртути РА-915+ с приставкой РП-91С. Методика М 01-46-2007.

30. Головацкая Е.А., Ляпина Е.Е. Распределение валовой ртути в профиле торфяных почв Западной Сибири / Сибирский экологический журнал. - 2009. - № 2. - С. 299-306.

31. Ляпина Е.Е. Экогеохимия ртути в природных средах Томского региона: дис. ... канд. геол.-минерал. наук. - Томск, 2012. $154 \mathrm{c.}$

32. Геохимия эпигейных лишайников водосборного бассейна Белого моря / В.П. Шевченко, О.С. Покровский, Д.П. Стародымова, Е.В. Васюкова, А.П. Лисицын, С.И. Дровнина, Н.С. Замбер, Н.М. Махнович, А.С. Саввичев, Й. Сонке // Доклады Академии наук. - 2013. - Т. 450. - № 1. - С.87-93.

33. Радченко А.И. Распределение ртути в ландшафтно-геохимических зонах Крыма // Минералогический журнал. - 1999. T. 21. - № 1. - C. 79-84.

34. Biogeochemical features of epiphytyc lichens from the area of the tailing of a gold-polymetallic deposit (Kemerovo region, Russia) comparative to a reference area / T.S. Bolshunova, L.P. Rikhvanov, A.M. Mezhibor, N.V. Baranovskaya, D.V. Yusupov // International Multidisciplinary Scientific GeoConference Surveying Geology and Mining Ecology Management, SGEM. - 2017. V. 17. - № 51. - P. 165-172.

35. Закутнова В.И., Пилипенко Т.А. Влияние тяжелых металлов на лишайники // Вестник ОГУ. - 2004. - № 12. - С. 112-116.

36. Biomonitoring of airborne metals using the Lichen Xanthoriaparietina in Kocaeli Province, Turkey / A.D. Demiray, I. Yolcubal, N.H. Akyol, G. Çobanoğlu // Ecological Indicators. - 2012. V. 18. - P. 632-643.

37. Biogeochemical characteristics of epiphitic lichen Lobariapulmonaria of the Barguzin nature reserve (the Republic of Buryatia, Russia) / T. Bolshunova, L. Rikhvanov, A. Mezhibor, L. Zhornyak, N. Baranovskaya, E. Eremina // Journal of Environmental Engineering and Landscape Management. - 2018. - V. 26. № 2. - C. 120-127.

38. Ориентировочные фоновые и допустимые биологические уровни некоторых тяжелых металлов в биосубстратах у населения, не имеющего с ними профессионального контакта. Критерии 
оценки экологической обстановки территорий для выявления зон чрезвычайной экологической ситуации и зон экологического бедствия. Приложение 1. Утверждено МПР РФ 30.11.1992. URL: http://www.consultant.ru/document/cons doc LAW 90799/37197b6e9878843ed021523902152b55a3767c 1c/ (дата обращения: 19.03.2018).

39. Новикова Л.Н., Новиков Ю.А. Геохимическая классификация ландшафтов Крыма и их техногенное загрязнение // Ученые записки Крымского федерального университета имени В.И. Вернадского. География. Геология. - 2008. - Т. 21. № 3. - С. 231-237.

40. Государственный доклад «0 состоянии и об охране окружающей среды Российской Федерации в 2015 году». - М.: Минприроды России; НИА-Природа, 2016. - 639 с.

Поступила 10.11.2018 г.

\section{Информация об авторах}

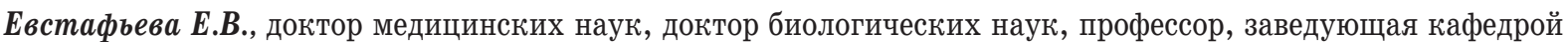
физиологии нормальной и лаборатории медико-экологического мониторинга Медицинской академии им. С.И. Георгиевского (структурное подразделение ФГАОУ ВО Крымский Федеральный Университет им. В.И. Вернадского).

Богданова $\boldsymbol{A}$.M., младший научный сотрудник Центральной научно-исследовательской лаборатории Медицинской академии им. С.И. Георгиевского (структурное подразделение ФГАОУ ВО Крымский Федеральный Университет им. В.И. Вернадского).

Большунова T.C., кандидат геолого-минералогических наук, ведущий инженер отдела экологического нормирования АО «ТомскНИПИнефть».

Барановская Н.В., доктор биологических наук, профессор Инженерной школы природных ресурсов Национального исследовательского Томского политехнического университета.

Ocunова H.A., кандидат химических наук, доцент Инженерной школы природных ресурсов Национального исследовательского Томского политехнического университета. 
UDC 550.47:574:504.064.36(470+571)

\title{
MERCURY CONTENT IN THE EPIPHYTIC LICHENS OF CRIMEA REPUBLIC
}

\author{
Elena V. Evstafeva', \\ e.evstafeva@mail.ru
}

\section{Anna M. Bogdanova', annuta2607@yandex.ru}

Tatiana S. Bolshunova ${ }^{2}$, BolshunovaTS@gmail.com

\section{Nataliya V. Baranovskaya³,} nata@tpu.ru

\author{
Nina A. Osipova ${ }^{3}$, \\ osipova@tpu.ru \\ 1 V.I. Vernadsky Crimean Federal University, Medical Academy Named after S.I. Georgievsky, \\ 5/7, Lenin Avenue, Simferopol, 295006, Russia. \\ 2 Tomsk Oil and Gas Research and Design Institute, \\ 72, Mira avenue, Tomsk, 634027, Russia. \\ ${ }^{3}$ National Research Tomsk Polytechnic University, \\ 30, Lenin Avenue, Tomsk, 634050, Russia.
}

In continuation of biomonitoring investigation of mercury on Crimean peninsula territory, aimed at systemic approach realization to determine its distribution between components of biosphere and processing of regional ecological standards for this and other metals, the mercury content was determined in epiphytic lichens that are natural planshet of atmospheric emission.

The aim of this study was to evaluate mercury content in the epiphytic lichens from the central, southern, southern-eastern and eastern districts of the Crimean peninsula.

Methods. Mercury content in lichens was determined by atomic adsorption analysis using mercury analyzer RA-915+ with PYRO-915 attachment in the laboratory of nuclear-geochemical methods of investigation in IISEC "Uranium geology» in National Research Tomsk Polytechnic University and by inductively coupled plasma-mass spectrometry in the accredited chemical analysis center «Plazma» (Tomsk). Results. Mercury content in epiphytic lichens in reserved southern territories and park zones of cities in central, eastern and near treatment facilities in southern-eastern regions of Crimea Republic varied from 0,054 to 0,306 mkg/g and did not differ from mercury level in background exposure on other territories of Russian Federation. At the same time there was an essential territorial heterogeneity of mercury content: in lichens from park zones of cities mercury content varied from 0,063 to 0,088 $\mathrm{mkg} / \mathrm{g}$, in mountainous and foothill areas of the southern Crimea it was twice higher. It can be explained by geomorphological and geochemical features of the Main ridge (deep breaks of orthogonal system with mercury ore occurrences and zones of geodynamic activity) and its barrier function for the air masses containing mercury sea aerosols. Besides, as it follows from the results of Convention LRTAP expert groups modeling, the significant contribution may be brought by Transboundary Air Pollution. The territorial heterogeneity of mercury content in lichens on conditionally background exposure territories together with intensive technological development of the Crimea dictate the necessity of the differentiated approach to ecological situation assessment in relation to such global and dangerous pollutant as mercury on different types of Crimea peninsular territories.

Key words:

Mercury, lichens, biosubstrate, bioindicator, Crimean peninsula.

The research was supported by the program of development of Crimea Federal University named after V.I. Vernadsky for 2015-2024 within implementation of academic mobility upon the project «Development of scientific research in experimental medicine» at National Research Tomsk Polytechnic University in 2016; within the Program of enhancement of National Research Tomsk Polytechnic University competitiveness among the leading world research centers; mercury analysis was supported by the RFBR within the scientific project no. 18-29-24212 \18.

\section{REFERENCES}

1. Spranger T., Lorenz U., Gregor H.D. Manual on methodologies and criteria for modeling and mapping critical loads and levels and air pollution effects, risks and trends. Berlin, Fed. Environ. Agency (Umweltbundesamt), UBA-Texte, 2004. 307 p.

2. Zhao J., Becker P.R., Meng X.Z. Securing a Strategy to Monitor Emerging Pollutants in the Regional and Global Environment. 2013 International Conference on Environmental Specimen
Banks. Environmental Science and Pollution Research International, 2015, vol. 22, no. 3, pp. 1555-1558.

3. IMOC - Inter organizational Programme for the Sound Management of Chemicals. A cooperative agreement among UNEP, ILO, FAO, WHO, UNIDO, UNITAR and OECD. Global Mercury Assessment. Geneva, UNEP Chemicals, 2002. 258 p.

4. Minamatskaya konventsiya o rtuti [Minamatsky convention on mercury]. UNEP, UN 2013. 65 p. Available at: http://www.mer- 
curyconvention.org/Portals/11/documents/Booklets/Minamata_convention_Russian.pdf (accessed 19 June 2018).

5. Pilotny proekt po formirovaniyu kadastra rtutnykh zagryazneniy $v R F$ [The Pilot project on formation of the inventory of mercury pollution in the Russian Federation]. Available at: https://www. mercury2017.ru/dokumenty (accessed 19 June 2018).

6. Rtutnoe zagryaznenie v Rossii: problemy i rekomendatsii [Mercury pollution in Russia: problems and recommendations]. Eds. A. Romanov, 0. Speranskaya, 0. Tsitser. Kolomna, Kolomna typography, 2016. $118 \mathrm{p}$.

7. Slootweg J., Posch M., Hettelingh J.-P. Progress in the Modelling of Critical Thresholds and Dynamic Modelling, including Impacts on Vegetation in Europe. CCE Status Report, 2010.182 p.

8. Evstafyeva E.V., Baranovskaya N.V., Tymchenko S.L., Bogdanova A.M., Naraev G.P., Sologub N.A., Narkovich D.V. Environmental and biomonitoring mercury research in the Crimean region. Bulletin of the Tomsk Polytechnic University. Geo Assets Engineering, 2017, vol. 328, no. 3, pp. 96-105. In Rus.

9. Evstafeva E.V. Otsenka ekologicheskogo riska dlya zdorovya na territorii Respubliki Krym [Assessing the environmental risk to health in the Republic of Crimea]. Problemy analiza riska, 2014, vol. 11, no. 5, pp. 30-38.

10. Evstafeva I.A. Osobennosti funktsionalnogo sostoyaniya tsentralnoy nervnoy i serdechnososudistoy sistem $v$ suyazi s soderzhaniem tyazhelykh metallov $v$ organizme podrostkov. Dis. Kand. nauk [Features of functional state of the central nervous and cardiovascular systems in relation to the content of heavy metals in the body of teenagers. Cand. Diss.]. Simferopol, 2003. 130 p.

11. Slyusarenko A.E. Immunologicheskaya reaktivnost organizma $v$ razlichnykh usloviyakh tekhnogennogo zagryazneniya sredy tyazhelymi metallami. Dis. Kand. nauk [Immunological reactivity of the organism in different conditions of technogenic pollution with heavy metals. Cand. Diss.]. Simferopol, 2003. 157 p.

12. Doklad «O sostoyanii i okhrane okruzhayushchey sredy na territorii Respubliki Krym v 2016 godu» [The report. About the state and protection of the environment on the territory of the Republic of Crimea in 2016]. Izhevsk, 000 «Print-2», 2017. 300 p.

13. Moiseenko V.G., Radomskaya V.I., Radomsky S.M., Piskunov Yu.G., Savinova T.A., Lenshin A.V. Intoxication of the human organism by the metal mercury. Bulletin of the Far East Branch of the Russian Academy of Sciences, 2004, no. 3, pp. 100-110. In Rus.

14. Element analysis of biological materials. Current problems and techniques with special reference to trace elements. Appendix II. Technical reports series, 1980, no. 197, pp. 351-367.

15. Kist A.A., Zhuk L.I. Human hair composition and the problems of global ecology. Tashkent, USSR, Institute of Nuclear Physics of the Uzbek Academy of Sciences, 1991. 60 p.

16. Bargagli R. Moss and lichen biomonitoring of atmospheric mercury: a review. Science of the Total Environment, 2016, vol. 572, pp. 216-231.

17. Isupova A.A., Yalaltdinova A.R. Kolichestvennoe opredelenie soderzhaniya rtuti v lishaynike vida Physciapul verulenta na primere promyshlennogo goroda Mezhdurechenska [Quantitative determination of mercury content in a lichen of the species Physciapul verulenta by the example of the industrial city of Mezhdurechensk]. Ekologicheskie problemy regiona i puti ikh resheniya. Materialy natsionalnoy nauchno-prakticheskoy konferentsii «Eko-BOOM» [Materials of the national scientific and practical conference «Eco-B00M»]. Omsk, 2016. pp. 143-147.

18. Bargagli R. Trace Elements in Terrestrial Plants: an Ecophysiological Approach to Biomonitoring and Biorecovery. B., Springer, 1998. $324 \mathrm{p}$.

19. Purvis 0.W., Williamson B.J., Spiro B., Udachin V., Mikhailova I.N., Dolgopolova A. Lichen monitoring as a potential tool in environmental forensics: case study of the $\mathrm{Cu}$ smelter and former mining town of Karabash, Russia. Geological Society, London, Special Publications, 2013, vol. 384, pp. 133-136.
20. Mezhibor A.M., Bolshunova T.S., Rikhvanov L.P. Geochemical features of sphagnum mosses and epiphytic lichens in oil and gas exploitation areas (the case of Western Siberia, Russia). Environmental Earth Sciences, 2016, vol. 75, no. 18, p. 1260.

21. Lambert K.F., Evers D.C., Warner K.A., King S.L., Selin N.E. Integrating Mercury Science and Policy in the Marine Context: Challenges and Opportunities. Environmental Research, 2012, no. 119, pp. 132-142.

22. Chen G., Chen X., Yan C., Wu X., Zeng G. Surveying mercury levels in hair, blood and urine of under 7-year old children from a coastal city in China. International journal of environmental research and public health, 2014, vol. 11, no. 11, pp. 12029-12041.

23. Rudneva I.I., Shevchenko N.F., Zalevskaya I.N., Zherko N.V. Biomonitoring of Coastal Waters of the Black Sea. Vodnyye resursy, 2005, vol. 32, no. 2, pp. 238-246. In Rus.

24. Oksner A.N. Opredelitel lishaynikov SSSR. Morfologiya, sistematika i geograficheskoe rasprostranenie [Lichen indicator in USSR. Morphology, systematics and geographical propagation]. Leningrad, Nauka Publ., 1974. Iss. 2, 284 p.

25. Yazikov Y.G., Baranovskaya N.V., Ignatova T.N. Ekologo-geokhimicheskaya otsenka territory rayona goroda po dannym biogeokhimicheskoy semki [Ecological and geochemical estimation of the territory of the city area according to biogeochemical survey data]. Tomsk, Tomsk Polytechnic University Publ. house, 2009. $32 \mathrm{p}$.

26. Bargagli R., Nimis P.L. Guidelines for the use of epiphytic lichens as biomonitors of atmospheric deposition of trace elements. Monitoring with Lichen - Monitoring Lichens. Dordrech, Kluwer, 2002. pp. 295-299.

27. Zyrina N.G., Malakhova S.G. Metodicheskie rekomendatsii po provedeniyu polevykh i laboratornykh issledovaniy pochv i rasteniy pri kontrole zagryazneniya okruzhayushchey sredy metallami [Methodological recommendations for conducting field and laboratory studies of soils and plants in the control of environmental pollution by metals]. Moscow, Gidrometeoizdat Publ., 1981. $187 \mathrm{p}$.

28. Lapshin V.B., Chichayeva M.A., Polevshchikov D.M., Matveyeva I.S., Grebennikova T.V., Kolesnikov M.V., Chikviladze G.N., Pletenev S.S., Syroyeshkin A.V. Basic research and developmental prototype of technology for express air quality control in coastal cities and resorts. Trudy Gosudarstvennogo okeanograficheskogo instituta, 2009, no. 212, pp. 308-322. In Rus.

29. Metodika vypolneniya izmereniy massovoy doli rtuti v probakh pihschevykh produktov, prodovolstvennogo syirya, kormov, kombikormov i syrya dlya ikh proizvodstva atomno-absorbtsionnym metodom s ispolzovaniem analizatora rtuti RA-915 s pristavkoy RP91S. Metodika M 01-46-2007 [Methods of measurement of mercury mass share in probes of foodstuff, food staples, forages, compound feeds and raw materials for their production by atomic adsorption analysis using mercury analyzer PA-915+ with an attachment RP-91C. Technique of M 01-46-2007].

30. Golovatskaya E.A., Lyapina E.E. Distribution of total mercury in peat soil profiles in West Siberia. Siberian Ecological Journal, 2009, no. 2, pp. 299-306. In Rus.

31. Lyapina Y.Y. Ekogeokhimiya rtuti v prirodnykh sredakh Tomskogo regiona. Dis. Kand. nauk [Ecogeochemistry of mercury in natural environments of Tomsk region. Cand. Diss.]. Tomsk, 2012. $154 \mathrm{p}$.

32. Shevchenko V.P., Pokrovskiy 0.S., Starodymova D.P., Vasyukova Y.V., Lisitsyn A.P., Drovnina S.I., Zamber N.S., Makhnovich N.M., Savvichev A.S., Sonke Y. Geochemistry of terricolous lichens in the White Sea catchment area. Doklady Akademii nauk, 2013, vol. 450, no. 1, pp. 87-93. In Rus.

33. Radchenko A.I. Raspredeleniye rtuti v landshaftno-geokhimicheskikh zonakh Kryma [Mercury distribution in landscapegeochemical areas of the Crimea]. Mineralogicheskiy zhurnal, 1999, vol. 21, no. 1, pp. 79-84. 
34. Bolshunova T.S., Rikhvanov L.P., Mezhibor A.M., Baranovskaya N.V., Yusupov D.V. Biogeochemical features of epiphytyc lichens from the area of the tailing of a gold-polymetallic deposit (Kemerovo region, Russia) comparative to a reference area. Inter national Multidisciplinary Scientific GeoConference Surveying Geology and Mining Ecology Management, SGEM, 2017, vol. 17, no. 51 , pp. $165-172$.

35. Zakutnova V.I., Pilipenko T.A. Influence of heavy metals on lichens. Vestnik OGU, 2004, no. 12, pp. 112-116. In Rus.

36. Demiray A.D., Yolcubal I., Akyol N.H., Çobanoglu G. Biomonito ring of airborne metals using the Lichen Xanthoria parietina in Kocaeli Province, Turkey. Ecological Indicators, 2012, vol. 18, pp. 632-643.

37. Bolshunova T., Rikhvanov L., Mezhibor A., Zhornyak L., Baranovskaya N., Eremina E. Biogeochemical characteristics of epiphitic lichen Lobariapulmonaria of the Barguzin nature reserve (the Republic of Buryatia, Russia). Journal of Environmental Engineering and Landscape Management, 2018, vol. 26, no. 2, pp. 120-127.

38. Orientirovochnye fonovye i dopustimye biologicheskie urovni nekotorykh tyazhelykh metallov $\mathrm{v}$ biosubstratakh u naseleniya, ne imeyushchego s nimi professionalnogo kontakta [Indicative back- ground and permissible biological levels of some heavy metals in biosubstrates of people without occupational exposure to them]. Kriterii otsenki ekologicheskoy obstanouki territoriy dlya vyyavleniya zon chrezvychaynoy ekologicheskoy situatsii i zon ekologicheskogo bedstviya [Criteria for assessing the ecological environment areas to identify areas of ecological emergency and ecological disaster zones]. Appendix 1, approved MNR RF 30.11.1992. Available at: http://www.consultant.ru/document/cons_doc_LAW 90799/37197b6e9878843ed021523902152b55a3767c1c/ (accessed 19 March 2018).

39. Novikova L.N., Novikov Y.A. Geochemical classification of Crimean landscapes and their technogenic pollution. Uchenye zapiski Krymskog ofederalnogo universiteta imeni V.I. Vernadskogo. Geografiya. Geologiya, 2008, vol. 21, no. 3, pp. 231-237. In Rus.

40. Gosudarstvennyiy doklad "O sostoyanii i ob okhrane okruzhayushchey sredy Rossiyskoy Federatsii v 2015 godu» [The state report. About state and protection of the environmental in Russian Federation in 2015]. Moscow, Ministry of Natural Resources and Environmental Protection of the Russian Federation; NIA-Priroda, 2016. $639 \mathrm{p}$.

Received: 10 November 2018.

\section{Information about the authors}

Elena V. Eustafeva, Dr. Sc., professor, Head of the Normal physiology department, V.I. Vernadsky Crimean Federal University, Medical Academy Named after S.I. Georgievsky.

Anna M. Bogdanova, junior researcher, V.I. Vernadsky Crimean Federal University, Medical Academy Named after S.I. Georgievsky.

Tatiana S. Bolshunova, Cand. Sc., engineer, Tomsk Oil and Gas Research and Design Institute.

Natalia V. Baranovskaya, Dr. Sc., professor, National Research Tomsk Polytechnic University.

Nina A. Osipova, Cand. Sc., associate professor, National Research Tomsk Polytechnic University. 